\title{
Experimental endocrine manipulation by contraceptive regimen in the male marmoset (Callithrix jacchus)
}

\author{
Joachim Wistuba, C Marc Luetjens ${ }^{\dagger}$, Jens Ehmcke ${ }^{\ddagger}$, Klaus Redmann, Oliver S Damm, \\ Antje Steinhoff, Reinhild Sandhowe-Klaverkamp, Eberhard Nieschlag, Manuela Simoni ${ }^{\S}$ \\ and Stefan Schlatt
}

Institute of Reproductive and Regenerative Biology, Centre of Reproductive Medicine and Andrology,
University of Münster, Albert-Schweitzer-Campus 1, Building D11, 48129 Münster, Germany

Correspondence should be addressed to J Wistuba; Email: joachim.wistuba@ukmuenster.de

${ }^{+} \mathrm{C} M$ Luetjens is now at Covance Laboratories, Kesselfeld 29, 48155 Münster, Germany

${ }^{\ddagger}$ J Ehmcke is now at Central Animal Facility of the Faculty of Medicine, University of Münster, Albert-Schweitzer-Campus 1 (A8), 48149 Münster, Germany

${ }^{\S} \mathrm{M}$ Simoni is now at Chair of Endocrinology, Department of Biomedicine, Metabolism and Neural Sciences, NOCSAE, University of Modena and Reggio Emilia, Via Giardini 1355, I-41126 Modena, Italy

\begin{abstract}
Marmosets are used as preclinical model in reproductive research. In contrast to other primates, they display short gestation times rendering this species valid for exploration of effects on fertility. However, their peculiar endocrine regulation differs from a those of macaques and humans. We subjected male marmosets to previously clinically tested hormonal regimens that are known to effectively suppress spermatogenesis. Beside a control group, seven groups (each $n=6)$ were investigated for different periods of up to 42 months: regimen I, (four groups) received testosterone undecanoate (TU) and norethisterone enanthate (NETE); regimen II, (two groups) received TU and NETE followed by NETE only; and regimen III, (one group) received NETE only. Testicular volume, cell ploidy and histology, endocrine changes and fertility were monitored weekly. TU and NETE and initial TU and NETE treatment followed by NETE failed to suppress spermatogenesis and fertility. Testicular volumes dropped, although spermatogenesis was only mildly affected; however, testicular cellular composition remained stable. Serum testosterone dropped when NETE was given alone but the animals remained fertile. Compared with controls, no significant changes were observed in sperm motility and fertility. Administration of TU and NETE affected testicular function only mildly, indicating that the regulatory role of chorionic gonadotrophin and testosterone on spermatogenesis is obviously limited and testicular function is maintained, although the endocrine axis is affected by the treatment. In conclusion, marmosets showed a different response to regimens of male contraception from macaques or men and have to be considered as a problematic model for preclinical trials of male hormonal contraception.

Reproduction (2013) $\mathbf{1 4 5}$ 439-451
\end{abstract}

\section{Introduction}

The concept of male hormonal contraception is based on interruption of spermatogenesis via gonadotrophin suppression. This can be achieved by administration of exogenous testosterone that, in addition to suppressing gonadotrophins and intratesticular steroid production, maintains androgenization. Several studies have shown that, in the human, testosterone alone effectively suppresses spermatogenesis down to azoospermia in almost all East Asian participants but only in about two thirds of Caucasian men, indicating the need for additional administration of a gestagen or a gonadotrophinreleasing hormone $(\mathrm{GNRH})$ antagonist to improve the effect (for review see Kamischke \& Nieschlag
(2004) and Nieschlag (2010)). Against the background of these findings, regimens based on testosterone formulations alone were no longer suggested for male contraception but combinations with gestagens (e.g. norethisterone enanthate (NETE) or levonorgestrel, which were shown to be effective in humans) were supposed to achieve higher efficiency rates (Nieschlag 2010). Among the several regimens proposed, the testosterone undecanoate (TU)/NETE combination is thought to be most promising because of its high effectiveness in achieving azoospermia (close to 100\%) and because this combination has been shown to be safe and reversible in short-term studies (Kamischke et al. 2002, Kamischke \& Nieschlag 2004); moreover, although NETE has no direct effect on the testis and the 
epididymis (Junaidi et al. 2005), it was found to have a beneficial suppressive effect on testosterone-induced prostate growth (Wistuba et al. 2012). However, to date, all studies have been of short duration (up to 1 year) and no information about reversibility and side effects after long-term treatment is available. Recently, in an ongoing long-term multicenter evaluation for efficacy testing of TU/NETE for hormonal male contraception guided by the WHO, a reasonable efficiency of this regimen for contraceptive purposes was revealed. However, the treatment was terminated because of unwanted side effects (CONRAD press release: Male Hormonal Contraceptive Trial Ending Early. April 22, 2011, http://www.conrad.org/news-pressreleases-63. html). Therefore, there is an obvious need for further exploration of hormonal male contraception in animal models, preferably in non-human primates (NHPs).

The common marmoset (Callithrix jacchus) is widely used as a primate model for human reproductive research (Li et al. 2005) because of the similarities in its testicular development, the organization of the seminiferous epithelium and germ cell stages (Weinbauer et al. 2001a, Wistuba et al. 2003, Luetjens et al. 2005, Mitchell et al. 2008, Albert et al. 2010). Furthermore, the marmoset's high fertility rate and early sexual maturity permit use of larger animal numbers for experimental studies, which allows the generation of unambiguous data (Millar et al. 2000). The marmoset has two further advantages: the possibility of fertility studies (long-term efficacy) and use of groups of animals at regular intervals for complete analysis of several tissues (side effects). Marmosets exhibit endocrine peculiarities, i.e. hormones involved in reproductive regulation as gonadotrophins and steroids are specifically different from those of other primates (Li et al. 2005, Luetjens et al. 2005). It was reported that due to low binding affinity of plasma steroid binding protein, high levels of free testosterone were observed in the serum of marmosets (Pugeat et al. 1984). Moreover, a generalized steroid resistance was suggested for New World Monkeys (e.g. Shinki et al. (1983), Lipsett et al. (1985) and Pryce et al. (2002)). Concerning testosterone, the permanent presence of enhanced levels could result in a certain resistance in the target organs (Takahashi et al. 1985, Li et al. 2005) and an accelerated clearance of exogenous androgens was reported (Mohle et al. 2002, reviewed in Li et al. (2005)). Owing to this specific endocrine condition, we adapted the dosing of TU in our experiments and administered $\sim 3.5$-fold higher dose compared with the amount recommended for human use (Kamischke et al. 2001, 2002, Meriggiola et al. 2005). However, before our experiments were performed, no experience existed about effects of TU/NETE on spermatogenesis in NHP species.

In order to test experiments, the accepted combined standard regimen used in humans and applied by the
WHO, we addressed the issue of whether the combination of TU/NETE can suppress spermatogenesis in the marmoset monkey and thereby induce infertility in this NHP. For this purpose, we conducted experiments using three treatment regimens: for regimen I, the male animals were administered TU and NETE for various periods, the regimen established and thought to be most effective in other primate models and in men; for regimen II, an initial administration of TU and NETE was followed by periods of NETE only, in order to assess effects of extended gonadotrophin suppression after the normal contraceptive hormone combination; in regimen III, only NETE was administered in order to examine the pure gestagen effect on male reproduction in this NHP. We analysed clinical and endocrine parameters as well as fertility in order to address the questions of whether the marmoset is a suitable animal model for male contraceptive trials, whether staggered treatment over various periods affects the male animals differently and whether thresholds in treatment duration exist affecting reversibility of a contraceptive effect.

\section{Results \\ Body weight}

In all treatment groups, moderate body weight gain was observed over the various treatment periods (Table 1). The strongest increase was found in group 3 (NETE only for 18 months, $14.8 \pm 2.3 \%$ ), while group 1 revealed the smallest gain (TU and NETE for 6 months, $2.3 \pm 5.1 \%$ ).

\section{Testicular and epididymal histology}

Testicular histology showed only mild changes. In most animals, almost normal spermatogenesis progress was found. Sometimes quantitatively reduced spermatogenesis occurred and rarely regions exhibiting mixed atrophy were observed (Fig. 1). Cross sections revealed the presence of morphologically normal spermatozoa in the epididymides of all experimental animals analysed.

\section{Testis volume}

Testis volume was expressed as relative bi-testicular volume, setting the higher of the two baseline values to $100 \%$. In all treatment groups, the testicular volume initially dropped (Fig. 2). In those groups administered TU and NETE over the entire experimental period (groups 1, 2, 4 and 6), testicular volume was reduced to $50-60 \%$ and remained at least below $70 \%$ of the baseline value until the groups were finally analysed. However, in group 3, in which a $40 \%$ loss was achieved due to NETE-only treatment, the testicular volume recovered to baseline before the experiment was ended (Fig. 2C). In those two groups receiving TU and NETE first and afterwards NETE only, a similar volume increase 


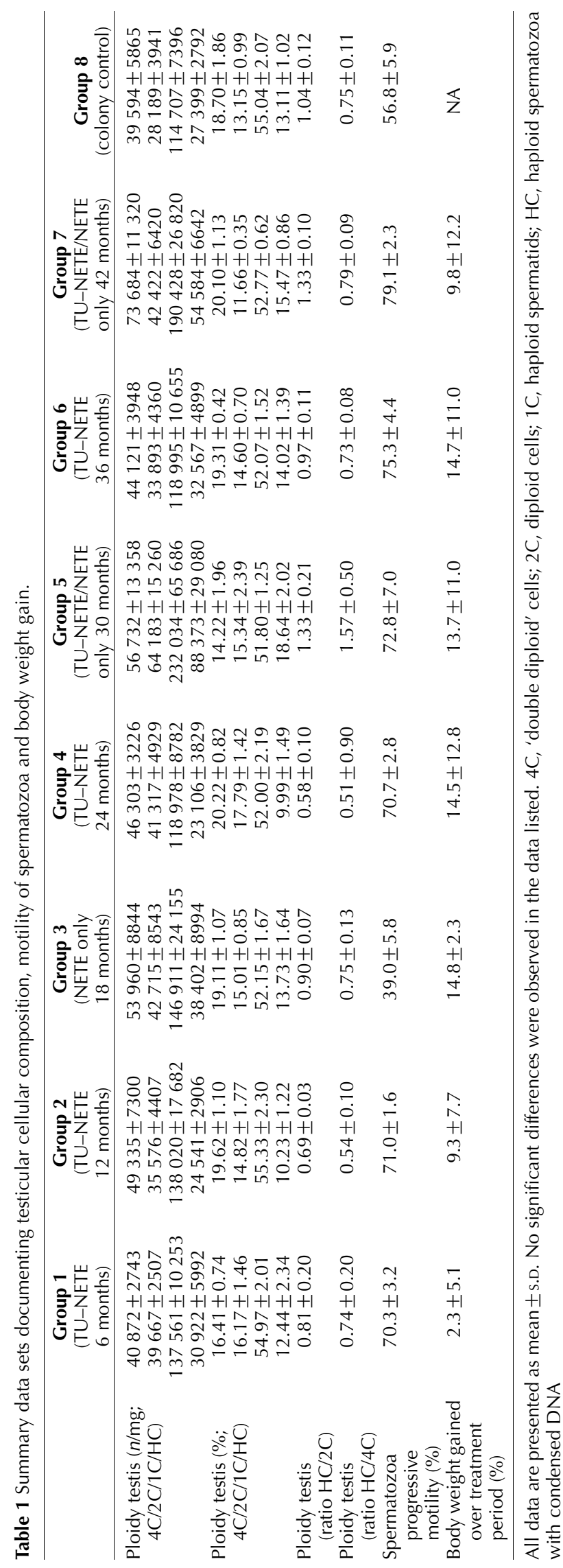

in the final experimental phase was observed, although in these two groups $(5,7)$ baseline levels were not fully reached (Fig. 2).

\section{Hormone measurements}

\section{Serum testosterone}

As expected, serum testosterone levels stayed in the physiological range in all treatment groups receiving TU and NETE over the entire study period (range: 20-140 nmol/l; Fig. 3). In groups 5 and 7 receiving the combined treatment during the initial phase of the study only and NETE alone afterwards, physiological serum testosterone levels were found as long as TU was administered and testosterone levels dropped when only NETE was given. While group 5 remained in a lower range $(<15 \mathrm{nmol} / \mathrm{l})$ until the end of the study period, values of serum testosterone in group 7 recovered at least to the lower normal range during the last 6 months of the experimental period (>20 nmol/l; Fig. 3). By contrast, in animals treated with NETE only for 18 months (group 3), serum testosterone was immediately suppressed and remained in a hypogonadal state for the entire duration of the experiment (Fig. 3).

\section{Intratesticular testosterone}

Compared with untreated controls, intratesticular testosterone (ITT) was significantly suppressed in group 1 (mean \pm s.E.M., $349.6 \pm 88.0 \mathrm{pmol} / \mathrm{g}$ testis), group $2(720.4 \pm 440.2 \mathrm{pmol} / \mathrm{g}$ testis), group 4 (181.5 $\pm 99.2 \mathrm{pmol} / \mathrm{g}$ testis$)$ and group $6(192.0 \pm 110.0 \mathrm{pmol} / \mathrm{g}$ testis) receiving TU and NETE over the entire study period (6, 12, 24 and 36 months respectively). ITT levels determined in groups 5 and 7 treated initially with TU and NETE before only NETE was administered for several months, values were intermediate (group 5, 1330.1 $\pm 814.6 \mathrm{pmol} / \mathrm{g}$ testis and group $7,788.5 \pm 250.8 \mathrm{pmol} / \mathrm{g}$ testis) but not significantly different from the controls. The same was true in group 3, treated with NETE only for 18 months, in which ITT was similar to the values found in control animals (group 3, 2998.8 $\pm 1889.8 \mathrm{pmol} / \mathrm{g}$ testis; controls, $4271.8 \pm 1051.3 \mathrm{pmol} / \mathrm{g}$ testis; Fig. 4A).

\section{Pituitary chorionic gonadotrophin}

Pituitary homogenates were analysed for chorionic gonadotrophin (CG) content. In all treatment groups, except group 7, CG levels were significantly lower compared with those in control samples, indicating endocrine suppression of the pituitary by the administration of TU and NETE or NETE only. The most effective suppression of CG production was observed in those groups treated with TU and NETE (groups 1, 2, 4 and 6) throughout the entire study period, exhibiting CG values below $2000 \mathrm{IU} / \mathrm{l} /$ organ (Fig. 4B). Similar values were 

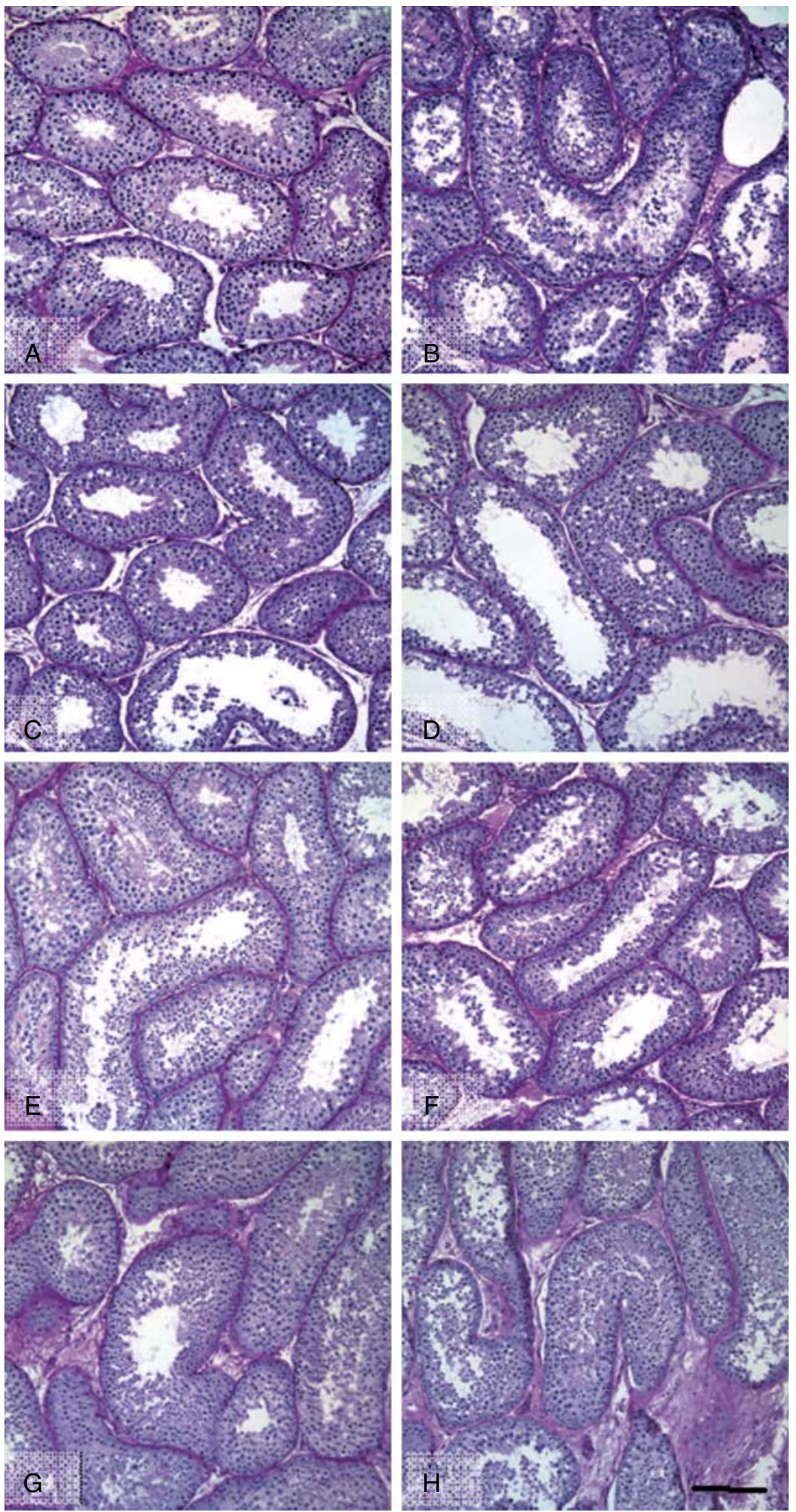

Figure 1 Testicular histology from the different treatment groups. (A) Control, (B) TU and NETE 6 months, (C) 12 months, (D) 24 months, (E) 36 months, (F) TU and NETE followed by NETE only (7 and 16 months) and (G) 23 and 26 months, (H) NETE only for 18 months. While controls exhibited completely normal spermatogenesis, cross sections from the treatment groups revealed predominately normal spermatogenic progress and very rarely disturbance up to mixed atrophy. In general, only very mild or no effects were observed. Regions with unaffected tubular organization were found in direct neighbourhood to disorganized or arrested tubules. PAS staining. Bars represent $250 \mu \mathrm{m}$ in the overview and $150 \mu \mathrm{m}$ in the detail micrographs. found in the monkeys of group 5, which were treated with TU and NETE for 7 months and with NETE only for another 23 months (Fig. 4B). Group 3 administered NETE only for 18 months revealed almost twofold higher CG values but their pituitaries were also significantly suppressed when compared with the organs of the control animals (Fig. 4B). Interestingly, group 7 treated with TU and NETE for 16 months and with NETE only for 

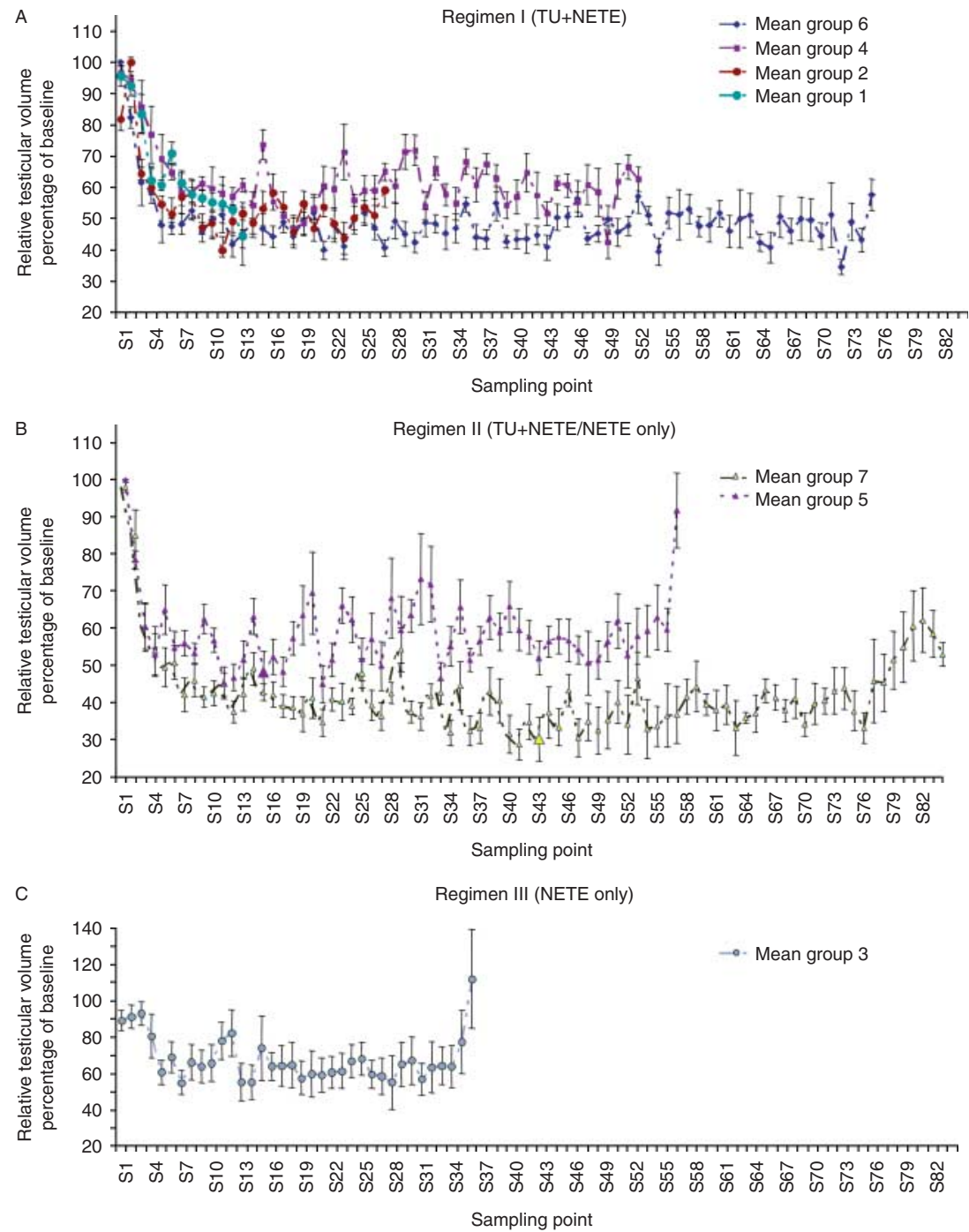

Figure 2 Changes in relative bi-testicular volume (mean \pm s.E.M.; the higher baseline value was set to $100 \%$ ). (A) In groups 1, 2, 4 and 6 administered TU and NETE over the entire experimental period, testicular volume was reduced to $50-60 \%$ and remained at least below $70 \%$ of baseline until the groups were analysed. (B) In groups 5 and 7 receiving TU and NETE first and afterwards NETE only, after initial reduction of testicular volume, volume increase in the final phase was observed. Bigger symbols mark the time point when administration regimen was changed to NETE only. (C) Group 3: NETE-only treatment resulted in a $40 \%$ loss of testicular volume. Testicular volume recovered to baseline under the NETE administration before the experiment ended. another 26 months on average exhibited CG values above $10000 \mathrm{U} / \mathrm{l}$, only slightly lower than those in the control monkeys (on average $>14000 \mathrm{IU} / \mathrm{l}$; Fig. 4B).

\section{Morphometric analysis of testicular composition}

Testis samples obtained from the animals of group 1 (TU and NETE 6 months), group 6 (TU and NETE 36 months), group 3 (NETE only 18 months) and group 8 (untreated control) were morphometrically analysed. Groups 1, 6 and 3 were chosen because they represent those most strongly affected by the treatment in terms of testicular volume drop. Measurement of tubular diameter, lumen diameter and epithelial height revealed that both tubular and lumen diameter shrank significantly in the treatment groups when compared with the controls, but epithelial height was not different from those observed in the control tissues (Fig. 5A). Calculating the ratio of lumen diameter and epithelial height, the significant correlation was confirmed, indicating that the testicular volume loss in the treated animals was caused by decreased secretion (Fig. 5B).

\section{Ploidy analysis of testicular tissue}

Ploidy analysis provided the proportions of the various testicular cell populations with regard to DNA content; i.e. 'double diploid' cells (4C fraction) covering the spermatocytes during meiosis, somatic and diploid germ cells ( $2 \mathrm{C}$ fraction), haploid spermatids (1C fraction) and testicular spermatozoa with condensed DNA (HC fraction). When absolute cell counts per weight unit of testicular tissue were plotted, ploidy analysis revealed similar cell distribution patterns for all groups treated with the combined administration of TU and NETE during the various experimental periods. For groups 1, 2, 4 and 6, as well as for group 3 treated with NETE only, these patterns were found to be not different from the control samples analysed (Table 1). 

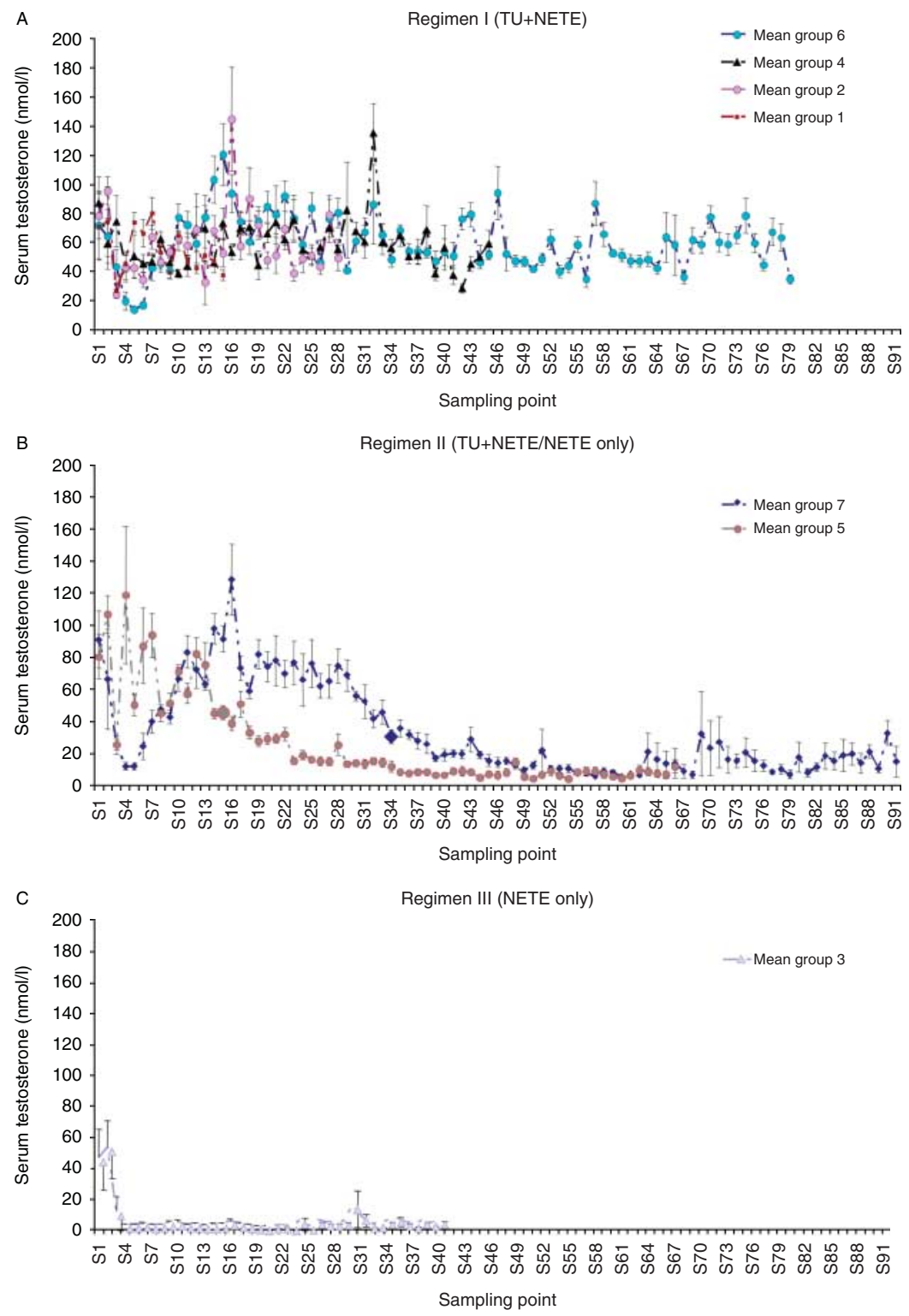

Figure 3 (A) Serum testosterone levels (mean \pm S.E.M.) were in the range of $20-140 \mathrm{nmol} / \mathrm{l}$ in groups $1,2,4$ and 6, receiving TU and NETE over the entire study period. (B) In groups 5 and 7 , receiving the combined treatment during the initial phase of the study and NETE only afterwards, serum testosterone was found in similar ranges as long as TU was injected but testosterone levels dropped after treatment was altered to NETE only (bigger symbols). While group 5 remained in a lower range $(<15 \mathrm{nmol} / \mathrm{l})$ until the end of the study, values in group 7 recovered at least to almost physiological levels during the last 6 months of the experimental period ( $>20 \mathrm{nmol} / \mathrm{l})$. (C) In group 3, receiving NETE only for 18 months, serum testosterone was immediately suppressed and remained in a hypogonadal state during the entire experiment.
Interestingly, the number of haploid cells $(1 \mathrm{C}, \mathrm{HC})$ was higher compared with all other groups including the control in groups 5 and 7, which were only initially treated with TU and NETE and subsequently NETE only for the rest of the experimental periods. In these two groups, the $2 \mathrm{C}$ and the $4 \mathrm{C}$ fractions also reached the highest values of all groups (Table 1). However, when expressed as relative proportions, all eight groups exhibited very similar distributions of the various cellular fractions (Table 1). Apart from group 4, which differred significantly from the control, the ratios of $\mathrm{HC} / 2 \mathrm{C}$ revealed no differences between the groups, nor were any differences between any groups found for the $\mathrm{HC} / 4 \mathrm{C}$ ratios (Table 1). Taken together, the evaluation of these results indicated a normal distribution of testicular cell fractions and normal ongoing spermatogenesis in the testes of all treated animals.

\section{Sperm motility}

Compared with the control group, sperm motility was increased in all treatment groups with the exception of group 3 (treated with NETE only, 18 months). While $56.7 \pm 5.9 \%$ (mean \pm s.E.M.) of the spermatozoa from epididymal samples of the controls were found to be motile, on average, motility for the experimental groups was above $70 \%$ (group 1, 70.3 \pm 3.2 ; group 2, 71.0 \pm 1.6 ; group 4, 70.7 \pm 2.7 ; group 5, 72.8 \pm 7.0 ; group 6, 75.3 \pm 4.4 and group $7,79.1 \pm 2.3$ ). By contrast, in group 3 only $39.0 \pm 5.8 \%$ of the sperm analysed were motile (Table 1 ). 

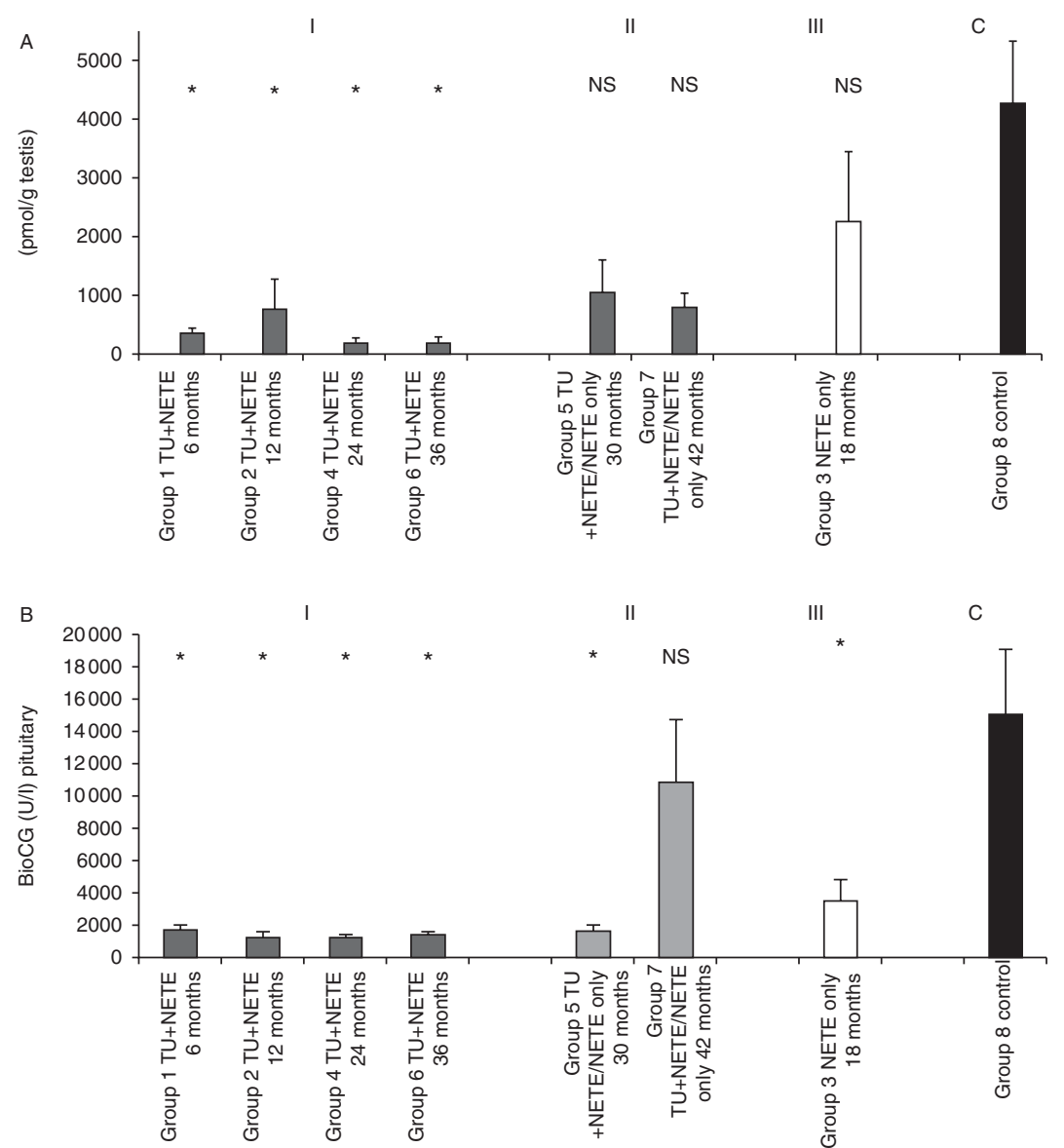

Figure 4 (A) Intratesticular testosterone (ITT; pmol/g testis) was significantly suppressed in groups 1, 2, 4 and 6 , which received TU and NETE over the entire study period $(6,12,24$ and 36 months respectively). In groups 5 and 7 , treated with TU and NETE/NETE only (30 and 42 months respectively), ITT values were intermediate but not longer different from controls. In group 3, treated with NETE only for 18 months, ITT was comparable to the values found in controls (mean \pm s.E.M.). (B) Pituitary BioCG from homogenates of the dissected organs were analysed for the CG content of the organ. In all treatment groups, except group 7, the CG levels were significantly lower than those of controls. CG production most effectively suppressed the groups treated consistently with TU and NETE and similar values were found in groups 3 and 5. However, group 7 treated with TU and NETE for 16 months and with NETE only for another 26 months exhibited average CG values above $10000 \mathrm{IU}$, only slightly lower than those of the controls. Different shades of columns indicate different treatment regimens. Columns marked with an asterisk represent values significantly lower compared with the control group $(p<0.05)$.
However, none of the differences observed reached the significance level (ANOVA).

\section{Fertility assessment}

Male monkeys from all groups were able to sire offspring independent of the duration of the various experimental periods and the administration regimen (Fig. 6), showing that the contraceptive treatment was insufficient to suppress the production of mature functional spermatozoa in the marmoset. Independently, whether the data were expressed as number of pups sired per treated animal and year of treatment or when the data were calculated as pregnancies per pair and year of treatment, no significant differences were found compared with the control pairs from the colony (ANOVA). Overall, male fertility was generally maintained under TU/NETE administration.

\section{Discussion}

Among NHPs, macaques in particular have previously been shown to be an excellent model for the endocrine regulation of reproduction and they reflect the human response to hormonal contraceptive regimen quite well
(Weinbauer \& Nieschlag 1999). However, the extended developmental time course and the more complex and expensive breeding conditions limit the use of these old-world monkeys because it is almost impossible to address fertility as an experimental endpoint and longterm studies are difficult to perform.

Establishing the marmoset monkey as a model for hormonal male contraception would provide an experimental NHP model by which the endpoint of fertility could be tested, the most prominent parameter in contraceptive trials. In our experiments, we therefore employed three regimens to analyse thoroughly the usefulness of the marmoset model in experimental settings addressing hormonal male contraception (e.g. for reproductive toxicology and or fertility suppression). We wanted to investigate whether the endocrine regulation of testicular function in the marmoset (Luetjens et al. 2005) and the strong social component regulating reproduction and natural fertility in this species (Abbott et al. 1988, Saltzman et al. 2009) allow studies that enable translation of findings to the human situation.

Additionally, the experimental design was set up to enable detection of putative long-term effects under contraceptive regimens, when following the animals 
A

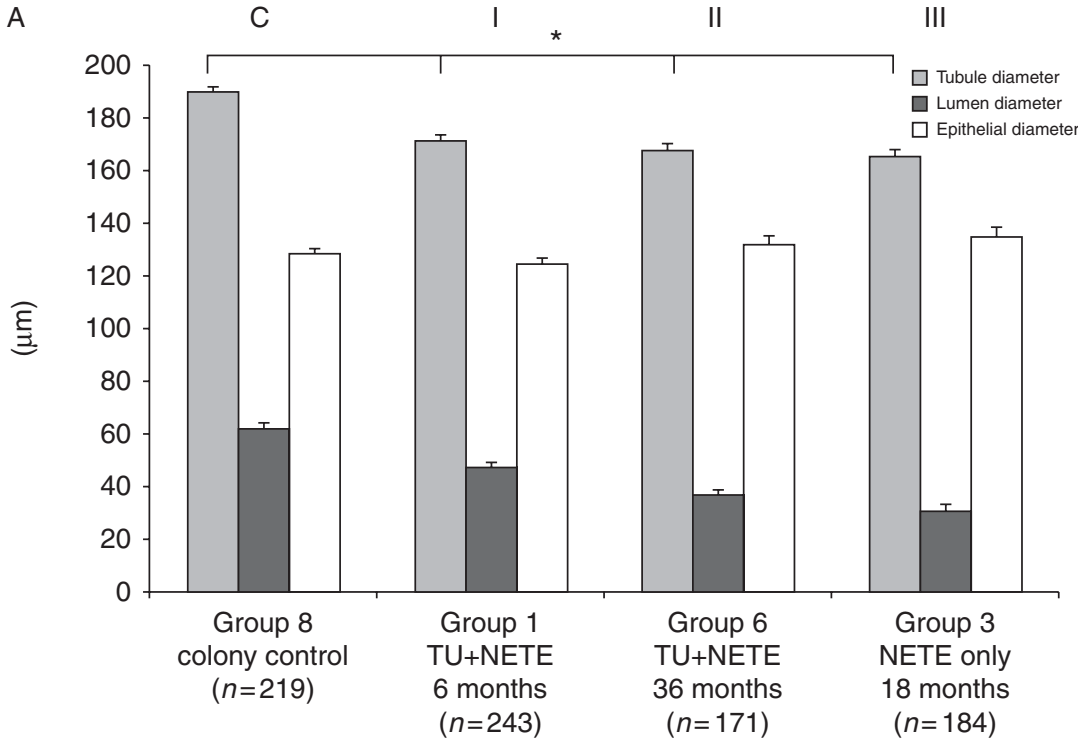

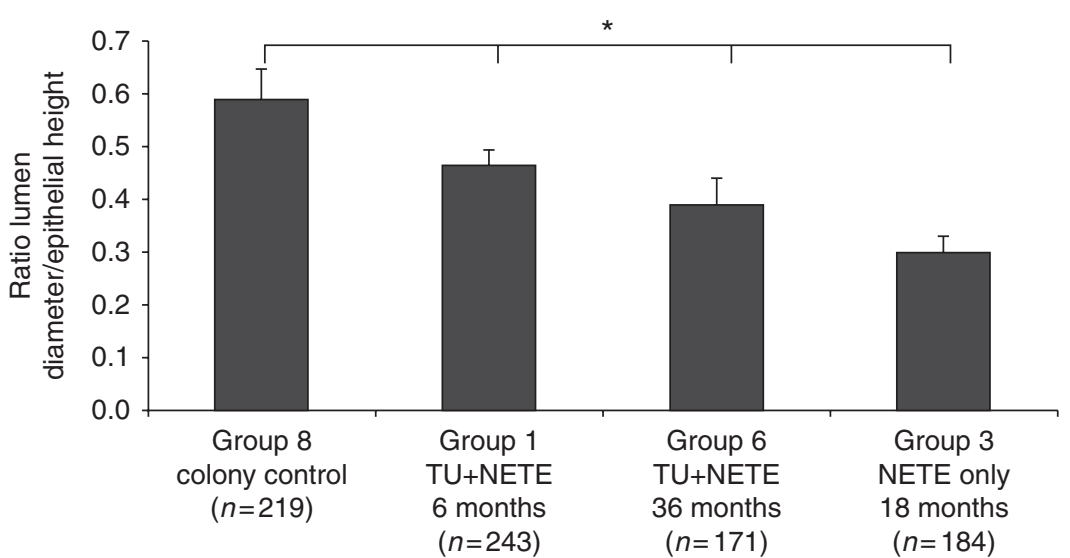

Figure 5 (A) Morphometric analysis. Tubular diameter, lumen diameter and epithelial height from testis samples of group 1 (TU and NETE 6 months), group 6 (TU and NETE 36 months) and group 3 (NETE only for 18 months) and group 8 (untreated control) revealed that both tubular diameter and lumen diameter shrank significantly in the treatment groups but epithelial height was not different to those observed in the controls. (B) The ratio of lumen diameter and epithelial height illustrated this significant correlation and indicated a secretion decrease of the seminiferous epithelium (values are mean \pm S.E.M). Columns marked with an asterisk represent values significantly lower compared with the control group $(\mathrm{p}<0.05)$. under treatment for up to 42 months, a period, which equals approximately one third of their adult lifetime.

One of the most surprising findings of the study against the background of the current WHO trial in humans (CONRAD press release: Male Hormonal Contraceptive Trial Ending Early. April 22, 2011, http://www.conrad. org/news-pressreleases-63.html) was that we did not observe any adverse effects on the marmosets health state related to the treatment, although the treatment was conducted up to 42 months. Albeit, marmoset monkeys exhibit a specific steroid resistance ( $\mathrm{Li}$ et al. 2005), our results showed that the selected doses for hormonal treatments were adequate. While ITT levels significantly declined, serum testosterone levels were maintained in a physiological range under TU and NETE treatment. In addition, pituitary CG production was affected as expected.

Treatment with the first regimen revealed that administration of TU and NETE, although affecting spermatogenesis, testis volume and fertility, is insufficient to achieve contraception in this animal model. While reduced testicular volume was found, the serum testosterone levels remained in the physiological range typical of adult animals (see Chandolia et al. (2006)) and the histological evaluation of testicular tissue showed mild effects of reduced spermatogenesis and rarely mixed atrophy. In order to establish the suppressive effects of NETE only and - indirectly - the impact of exogenous testosterone spermatogenesis in Callithrix jacchus - either after initial co-administration with TU or by direct use of NETE only - we added the two treatment groups in which, after TU/NETE administration, NETE only was administered (extended gestagen effect, regimen II) and one group that received NETE only (regimen III). The rationale for choosing this study design was that the regulation of male reproduction differed from that observed in old-world monkeys and great apes and is more strongly dependent on gonadotrophic action of CG (Gromoll et al. 2003, Müller et al. 2004). However, a similar picture was observed when, after 


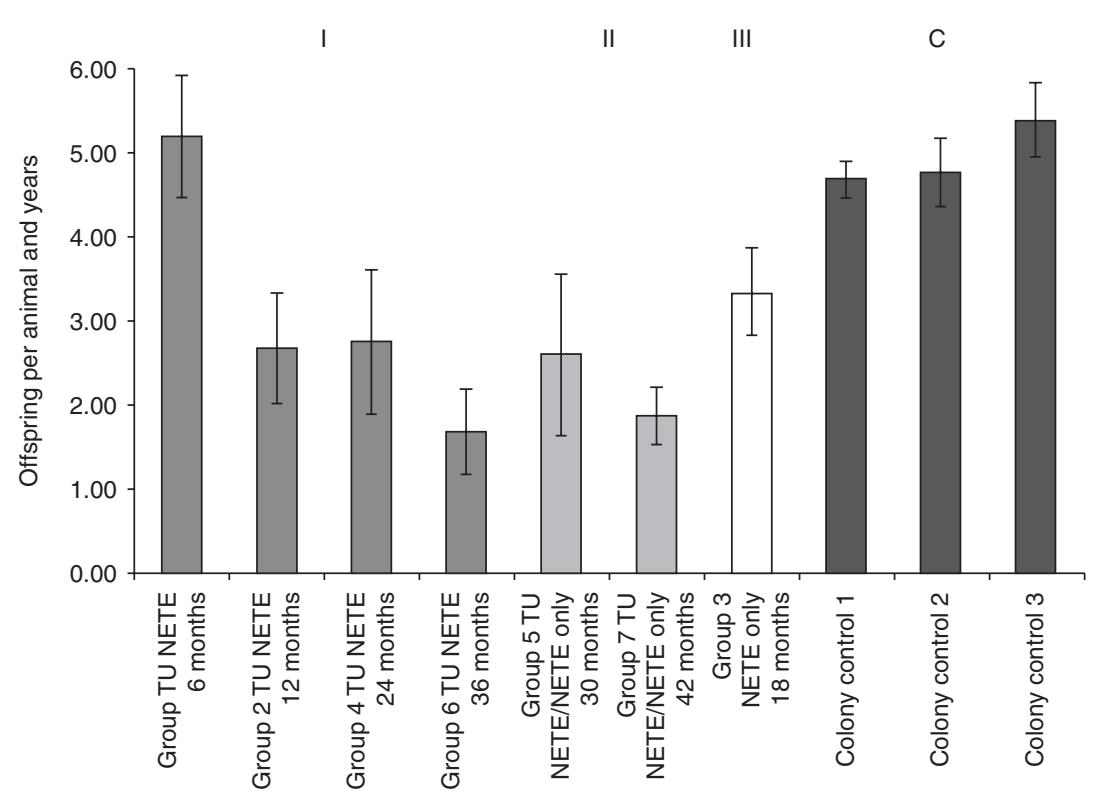

Figure 6 Offspring per animal and year of treatment. Control data were obtained from untreated pairs randomly selected from our breeding colony. No significant drop in fertility was found in the treatment groups when compared with the controls (ANOVA, values are mean \pm s.D.).

Different shades of columns indicate different treatment regimens. initial combined TU and NETE treatment, NETE only was given subsequently. If NETE only was administered, serum testosterone concentrations also dropped, but the animals remained fertile, also indicating that lowered testosterone levels did not provoke reduced sexual motivation or even absence of intercourse, as has been observed in humans. Compared with untreated control pairs from our colony, the number of offspring sired was reduced when the period of contraceptive treatment exceeded 6 months.

As expected by the treatment, we observed testosterone to be suppressed in serum under NETE treatment as well as in the testis when TU and NETE was administered, but we did not find sufficient suppression of spermatogenesis. There have been previous reports showing that testosterone alone is able to stimulate and maintain spermatogenesis in NHPs to some extent (Marshall et al. 1983, 1986). However, this does not explain our findings sufficiently. When NETE only was administered, serum testosterone was suppressed but ITT levels were maintained at a state that might have been adequate to maintain spermatogenesis. The same was true under the TU and NETE/NETE-only regimen. However, when TU and NETE were injected in combination, serum testosterone levels remained physiological, but ITT was significantly suppressed. Nevertheless, spermatogenesis was ongoing. This indicates that spermatogenic progression must be driven by regulatory endocrine mechanisms other than those of other primates such as old-world monkeys, great apes and humans.

The regulation of reproduction in marmosets is extremely dependent on the social status of the individual animal. This is a unique feature among available NHP models (Saltzman et al. 2009). In males, there are no data available on whether spermatogenesis is suppressed to some extent; however, it has been demonstrated that offspring are almost exclusively sired by the dominant male (Nievergelt et al. 2000) and supported by the lack of sexual dimorphism in marmosets, a monogamous mating system was suggested (Abbott \& Hearn 1978). In females, it was demonstrated that a subordinate social position of the animals within a family group acts as a natural contraceptive, being fully reversible once the animals reach alpha position within their groups or are housed individually with a partner. Such females, for example, start to cycle immediately (Abbott et al. 1988). As the androgen levels of male and female NHPs were shown to be linked also to behavioural traits that influence social rank (Batty et al. 1986, Ross et al. 2004), it might be that, specifically in the marmoset, androgens play a minor role in the regulation of the reproductive organs but are of higher importance for maintenance of social status compared with other primate species. This assumption could explain why we observed complete spermatogenesis and maintained fertility in the treated males, although serum testosterone as well as pituitary CG responded to the TU/NETE treatment largely as expected. Recently, it was shown that the reproductive endocrinology of new-world monkeys differs from oldworld monkeys, great apes and humans in terms of the gonadotrophins luteinizing hormone (LH) and CG. In the course of evolution, this hormone system has completely lost $\mathrm{LH}$ expression and CG has taken over all regulatory functions of LH in these monkeys (Gromoll et al. 2003, Luetjens et al. 2005).

However, in marmosets, FSH was recently found to act similarly to $\mathrm{FSH}$ in other primates when tested for superovulation purposes (Luetjens \& Wesselmann 2007, 
Müller et al. 2011). The combined treatment with TU and NETE was ineffective in interrupting fertility in the male marmosets, had mild suppressive effects on spermatogenesis and altered neither testicular composition nor the production or function of spermatozoa. We assume that for the maintenance of testicular function, the low levels of pituitary CG and corresponding low levels of ITT are sufficient to maintain spermatogenic progress in male marmosets. The exogenous hormone treatment showed obvious and expected endocrine effects but did not provoke the same level of spermatogenic disruption when compared with macaques or men. This is particularly surprising considering previous observations reporting a steroid resistance in New World Monkeys (Li et al. 2005). The marmoset seminiferous epithelium appears to be fully functional at very low levels of ITT, suggesting that the mechanisms of the proposed steroid resistance must be highly unusual. An alternative explanation could be found in the effects of FSH. This hormone is less affected by the exogenous treatment and plays an important role in primate spermatogenesis (Weinbauer et al. 2001b). It is likely that $\mathrm{FSH}$ plays an important role in the regulation of spermatogenesis in the marmoset. Unfortunately, no reliable assay is currently available to determine FSH levels in marmoset serum, which renders any changes in $\mathrm{FSH}$ levels and the role of FSH in the marmoset testis speculative. As an indirect readout, our morphometric data could be regarded as a bioassay for FSH action. A decline of seminiferous lumen diameter has previously been correlated with FSH-dependent Sertoli cell secretion (Selice et al. 2011). As we show a loss of luminal fluid as a main explanation for the drop in testicular volume, a decline of serum FSH levels leading to a decline of fluid secretion from Sertoli cells can be assumed. However, with regard to the steroid resistance observed in other organs, this could point to exclusion of the Sertoli cell function from this resistance.

Therefore, concerning the mechanism underlying the treatment failure, we can only speculate that in the marmoset either the treatment effect might have influenced Sertoli cell function to some extent but not the mediation of FSH action needed for maintenance of spermatogenesis or that because of the function of androgens being predominantly important for social hierarchy, a very low amount of CG and testosterone is still sufficient to maintain spermatogenesis. The latter would mean that in marmosets, these threshold levels would be by far lower than in other monkey species. Biologically, this might make sense: a male with low testosterone would avoid social conflicts but could still reproduce. This would also be consistent with the sexual behaviour observed in the hypogonadal males during the study, which copulated and sired offspring although the serum testosterone levels were completely suppressed (NETE-only treatment), indicating that sexual behaviour may be almost independent of high blood androgen levels.

Concluding our findings, the marmoset is a NHP model that would facilitate the measurement of fertility as an endpoint in a contraceptive trial but is obviously resistant to TU and NETE, which were shown to be effective suppressors of spermatogenesis in humans (Kamischke et al. 2002, Kamischke \& Nieschlag 2004, Meriggiola et al. 2005). Although testicular volumes dropped and the endocrine axis responded as expected, fertility was, if at all, only mildly influenced by the administration of androgens and progestins and a reliable contraceptive effect of TU and NETE treatment is lacking in this animal model. Our observations point to two possible explanations: either the testicular function of male marmosets requires a smaller amount of androgens (i.e. ITT is sufficient at a lower threshold value) or it is less dependent on androgens compared with other primates. Thus, because of their unusual response, the use of these monkeys for studies aiming at the proof of efficiency of hormonal male contraception in humans must be considered problematic.

\section{Materials and Methods}

\section{Animals}

Throughout the experimental period, the monkeys from our breeding colony were kept in pairs under a $12 \mathrm{~h}$ light: $12 \mathrm{~h}$ darkness regimen and fed pelleted food from Altromin (Lage, Germany) composed for marmosets together with beef or chicken meat and a daily supplement of fresh fruits and vegetables. They had unlimited access to tap water. Housing and exercise conditions were identical for all animals during the experimental period. In total, eight groups of adult male marmosets ( $n=6$ /group) were assigned to the experimental groups. One untreated group (group 8) from our colony served as an endpoint control. Groups 1, 2, 4 and 6 received TU (25 mg/kg body weight i.m. every 3 weeks) and NETE (70 mg, i.m. every three weeks) for 6, 12, 24 and 36 months respectively (regimen I). Groups 5 and 7 received TU and NETE/NETE only (regimen II, 7 and 16 months TU/NETE followed by 23 and 26 months NETE only respectively). Group 3 was treated with NETE only (regimen III, 18 months). Doses were chosen according to protocols shown to be effective in NHPs in previous studies (Junaidi et al. 2005, Wistuba et al. 2005, 2012). Table 2 summarizes the experimental design. Animals were regularly weighed at monthly intervals, and blood samples ( $\sim 500 \mu \mathrm{l} / \mathrm{sample})$ were drawn every 2 weeks and serum was stored. The treated males were caged with females of proven fertility after the third TU injection (20 weeks after the start of the study) and pregnancies and offspring sired during the mating were recorded.

At study end, the animals were anaesthetized with Ketanest ( $0.2 \mathrm{ml} / 100 \mathrm{~g}$ body weight) and killed by exsanguination. Body weight was recorded, and trunk blood was collected and stored at $-20{ }^{\circ} \mathrm{C}$. Testes, pituitaries and epididymides were removed and samples were snap-frozen or fixed in Bouin's solution for 
Table 2 Regimens and grouping of the experimental animals.

\begin{tabular}{|c|c|c|c|c|c|}
\hline Group & $\begin{array}{l}\text { Treatment (TU, } 25 \mathrm{mg} / \mathrm{kg} \\
\text { BW; NETE, } 70 \mathrm{mg} \\
\text { dose every } 3 \text { weeks) }\end{array}$ & $\begin{array}{c}\text { Treatment } \\
\text { regimen }\end{array}$ & $\begin{array}{c}\text { Duration of } \\
\text { treatment } \\
\text { (months) }\end{array}$ & Purpose & $\begin{array}{c}\text { Number of } \\
\text { animals entering } \\
\text { the study }\end{array}$ \\
\hline 1 & TU + NETE & I & 6 & Establishing contraceptive regimen & 6 \\
\hline 2 & $\mathrm{TU}+\mathrm{NETE}$ & I & 12 & Establishing contraceptive regimen & 6 \\
\hline 4 & $\mathrm{TU}+\mathrm{NETE}$ & 1 & 24 & Establishing contraceptive regimen & 6 \\
\hline 6 & TU + NETE & I & 36 & Establishing contraceptive regimen & 6 \\
\hline 5 & TU + NETE/NETE only & II & $7 / 16$ & Extended gestagen effects & 6 \\
\hline 7 & TU + NETE/NETE only & II & $23 / 26$ & Extended gestagen effects & 6 \\
\hline 3 & NETE only & III & 18 & Effect of gestagen alone & 6 \\
\hline 8 & None & Control & - & Endpoint control & 6 \\
\hline Colony controls & None & Control & - & Fertility control & $18(3 \times 6)$ \\
\hline
\end{tabular}

Both hormones were applied by i.m. injections.

1 day, before they were transferred into $70 \%$ ethanol and stored. As a result of wasting syndrome (Logan \& Khan 1996, Gore et al. 2001, Sousa et al. 2008), four of the 48 animals died during the study, unrelated to the treatment. Data from those monkeys were included in the evaluation until the time point when they started to lose weight. The experimental work was performed in accordance with the German Federal Law on the Care and Use of Laboratory Animals (LANuV NRW Licence no. G23/2006).

\section{NETE and testosterone preparation}

TU (3-oxoandrost-4-ene-17 $\beta$-yl-undecanoate; $250 \mathrm{mg} / \mathrm{ml}$ ) as well as NETE $(200 \mathrm{mg} / \mathrm{ml})$, both dissolved in castor oil, were provided by Schering AG (currently Bayer Pharma AG).

\section{Testis volume}

Testicular volume was calculated applying a formula for an ellipsoid from length and width measures of the testis using Vernier callipers as described previously (Weinbauer et al. 1998, Junaidi et al. 2005).

\section{Hormone measurements}

ITT and serum testosterone were determined as described by Chandolia et al. (1991, 2006). For ITT, frozen testicular tissue samples were homogenized in $250 \mu$ PBS buffer and dissolved by ultrasound. For the double antibody RIA, a iodinated tracer (testosterone-3-(O-carboxymethyl) oximino-2- $\left[{ }^{125} \mathrm{I}\right]$ iodohistamine; Amersham International) and an antiserum generated in rabbits against testosterone-3 (carboxymethyloxime)-BSA were used (Nieschlag \& Loriaux 1972). The second antibody reaction required two components: rabbit $\gamma$ globulin and anti-rabbit IgG immunoprecipitation reagent. Recovery was tracked by addition of tracing amounts of $\left[1 \beta, 2 \beta-{ }^{3} \mathrm{H}\right]$ testosterone (NEN Life Science Products, Boston, MA, USA). The intra- and inter-assay coefficients of variation (CV) were 6.1 and $8.7 \%$ respectively. Assay detection limit was $0.68 \mathrm{nmol} / \mathrm{l}$. Serum testosterone was measured by RIA as described previously (Chandolia et al. 1991). Each sample was assessed in duplicate after extraction with diethyl ether. The intra- and inter-assay CV were 5.9 and $7.8 \%$ respectively and the assay detection limit was $0.68 \mathrm{nmol} / \mathrm{l}$.
BioCG of pituitary homogenates was assessed by an in vitro bioassay making use of murine Leydig cells as previously reported (Müller et al. 2004, Chandolia et al. 2006). The intraand inter-assay CV were 8.4 and $20.5 \%$ respectively. The assay sensitivity for BioCG was $88 \mathrm{IU} / \mathrm{l}$ in terms of WHO standard 78/549.

\section{Testicular and epididymal histology}

Bouin-fixed samples were routinely embedded in paraffin and cut into $3 \mu \mathrm{m}$ sections that were PAS stained. Testicular cross sections were evaluated for the state of spermatogenic progress and epididymides were examined for the presence of sperm. Slides were evaluated and documented using an Axioskop (Zeiss, Oberkochen, Germany).

\section{Morphometric analysis of testicular composition}

Testes obtained from animals of four different treatment groups, each representative for one treatment regimen including the control group, were Bouin-fixed and paraffin embedded. Sections of $5 \mu \mathrm{m}$ thickness of the individual testes samples of group $1(n=6)$, group $6(n=5)$, group $3(n=5)$ and group 8 $(n=6)$ were PAS stained and subsequently micrographs taken at 20-fold magnification were then analysed by one investigator (A Steinhoff) blinded to the treatment state of the animals. Micrographs were analysed by measurement of epithelial height, tubular and luminar diameter after calibration via Cell Sense Standard software (Olympus Europa Holding $\mathrm{GmbH}$, Hamburg, Germany). At least 170 tubules were analysed per group. Additionally, a grid of 25 points was projected on at least five photos of the stained tissue sections in which it was determined whether the points were either projected on epithelium, lumen or interstitium in the individual section. Thus, it was possible to assess the distribution of the tissue compartments from 125 point counts.

\section{Ploidy analysis of testicular tissue by flow cytometry}

Flow cytometry was performed as described previously (Wistuba et al. 2003, Chandolia et al. 2006); briefly, parts of frozen testicular tissue were dissected and thawed in PBS at room temperature. About 10-20 mg tissue were minced for $1 \mathrm{~min}$ in staining buffer (PBS (supplemented with $1 \mathrm{mg} / \mathrm{ml}$ 
BSA), propidium iodide $(2.5 \mathrm{mg} / \mathrm{ml})$, RNase $(10 \mathrm{mg} / \mathrm{ml})$ and $0.1 \%$ Triton X-100 in PBS); homogenized for $2 \times 6 \mathrm{~s}$ with an Ultra-Turrax T8 (IKA, Staufen, Germany) and 12 strokes of an Eppendorf EDOS 5222, followed by filtration through a $50 \mu \mathrm{m}$ mesh sieve (Celltrics, Partec, Münster, Germany). The homogenate was incubated for further 25 min (room temperature) in staining buffer in the dark. By assessment of DNA content with a flow cytometer FC 500 (Beckman-Coulter, Krefeld, Germany), the number of elongated haploid cells ( $\mathrm{HC})$, round spermatids (1C), spermatogonial and somatic cells (2C), cells in S-phase of the cycle and tetraploid cells comprising mainly primary spermatocytes and G-2 spermatogonia cells (4C) were quantified and their proportions were calculated.

\section{Sperm motility}

Motility of spermatozoa was assessed from samples taken from the proximal cauda epididymis immediately after dissection of the organ (according to Damm \& Cooper (2010)). Sperm were diluted with warm Biggers-Whitten-Whittingham (BWW) medium (at $37^{\circ} \mathrm{C}$, see Biggers et al. (1971)) supplemented with $12 \mathrm{mg} / \mathrm{ml} \mathrm{BSA}$, adjusted at caudal isotonicity $(310 \mathrm{mmol} / \mathrm{kg}$ ) and the proportion of forward progressive living sperm was determined.

\section{Fertility assessment}

Male animals under treatment were mated to females of proven fertility. For comparability, the reproductive success was calculated as follows: number of offspring sired in the efficacy phase per animal and year of treatment. In group 6, data were calculated from five males, as for this group one female animal had to be excluded for reasons unrelated to the study. Eighteen breeding pairs from our colony were randomly assigned to three control groups in order to achieve comparable group sizes ('colony controls', $n=6$ pairs per group).

\section{Statistical analysis}

All data were expressed as mean \pm s.E.M. and analysed either by Student's $t$-test when appropriate or by ANOVA with a significance level set to $P<0.05$. Computations were performed using the statistical software package SIGMASTAT 3.5 (Systat Software GmbH, Erkrath, Germany).

\section{Declaration of interest}

The authors declare that there is no conflict of interest that could be perceived as prejudicing the impartiality of the research reported.

\section{Funding}

This work was supported by a grant of the Deutsche Forschungsgemeinschaft; DFG project no. SI 526/2-1.

\section{Acknowledgements}

The authors are indebted to S Rehr, J Körber, M Heuermann and $\mathrm{G}$ Stelke for the excellent technical assistance. The language editing of the manuscript by $S$ Nieschlag $M A$ is kindly acknowledged.

\section{References}

Abbott DH \& Hearn JP 1978 Physical, hormonal and behavioural aspects of sexual development in the marmoset monkey, Callithrix jacchus. Journal of Reproduction and Fertility 53 155-166. (doi:10.1530/jrf.0. 0530155)

Abbott DH, Hodges JK \& George LM 1988 Social status controls LH secretion and ovulation in female marmoset monkeys (Callithrix jacchus). Journal of Endocrinology 117 329-339. (doi:10.1677/joe.0. 1170329)

Albert S, Ehmcke J, Wistuba J, Eildermann K, Behr R, Schlatt S \& Gromoll J 2010 Germ cell dynamics in the testis of the postnatal common marmoset monkey testis (Callithrix jacchus). Reproduction 140 733-742. (doi:10.1530/REP-10-0235)

Batty KA, Herbert J, Keverne EB \& Vellucci SV 1986 Differences in blood levels of androgens in female talapoin monkeys related to their social status. Neuroendocrinology 44 347-354. (doi:10.1159/000124667)

Biggers JD, Whitten WK \& Whittingham DG 1971 The culture of mouse embryos in vitro. In Methods of Mammalian Embryology, 1st edn, pp 86-116. Ed. JC Daniel. San Francisco: Freeman.

Chandolia RK, Weinbauer GF, Simoni M, Behre HM \& Nieschlag E 1991 Comparative effects of chronic administration of the non-steroidal antiandrogens flutamide and casodex on the reproductive system of the adult male rat. Acta Endocrinologica 125 547-555. (doi:10.1530/ acta.0.1250547)

Chandolia RK, Luetjens CM, Wistuba J, Yeung CH, Nieschlag E \& Simoni M 2006 Changes in endocrine profile and reproductive organs during the onset of puberty in the marmoset monkey (Callithrix jacchus). Reproduction 132 359-367. (doi:10.1530/rep.1.01186)

Damm OS \& Cooper TG 2010 Maturation of sperm volume regulation in the rat epididymis. Asian Journal of Andrology 12 57-590. (doi:10.1038/ aja.2010.50)

Gore MA, Brandes F, Kaup FJ, Lenzner R, Mothes T \& Osman AA 2001 Callitrichid nutrition and food sensitivity. Journal of Medical Primatology 30 179-184. (doi:10.1111/j.1600-0684.2001.tb00007.x)

Gromoll J, Wistuba J, Terwort N, Godmann M, Müller T \& Simoni M 2003 A new subclass of the luteinizing hormone/chorionic gonadotropin receptor lacking exon 10 messenger RNA in the New World Monkey (Platyrrhini) lineage. Biology of Reproduction 69 75-80. (doi:10.1095/ biolreprod.102.014902)

Junaidi A, Luetjens CM, Wistuba J, Kamischke A, Yeung CH, Simoni M \& Nieschlag E 2005 Norethisterone enanthate has neither a direct effect on the testis nor on the epididymis: a study in adult male cynomolgus monkeys (Macaca fascicularis). European Journal of Endocrinology 152 655-661. (doi:10.1530/eje.1.01878)

Kamischke A \& Nieschlag E 2004 Progress towards hormonal male contraception. Trends in Pharmacological Sciences 25 49-57. (doi:10.1016/ j.tips.2003.11.009)

Kamischke A, Venherm S, Plöger D, von Eckardstein S \& Nieschlag E 2001 Intramuscular testosterone undecanoate and norethisterone enanthate in a clinical trial for male contraception. Journal of Clinical Endocrinology and Metabolism 86 303-309. (doi:10.1210/jc.86.1.303)

Kamischke A, Heuermann T, Krüger K, von Eckardstein S, Schellschmidt I, Rübig A \& Nieschlag E 2002 An effective hormonal male contraceptive using testosterone undecanoate with oral or injectable norethisterone preparations. Journal of Clinical Endocrinology and Metabolism 87 530-539. (doi:10.1210/jc.87.2.530)

Li LH, Donald JM \& Golub MS 2005 Review on testicular development, structure, function, and regulation in common marmoset. Birth Defects Research. Part B, Developmental and Reproductive Toxicology $\mathbf{7 4}$ 450-469. (doi:10.1002/bdrb.20057) 
Lipsett MB, Chrousos GP, Tomita M, Brandon DD \& Loriaux DL 1985 The defective glucocorticoid receptor in man and nonhuman primates. Recent Progress in Hormone Research 41 199-247.

Logan AC \& Khan KN 1996 Clinical pathologic changes in two marmosets with wasting syndrome. Toxicologic Pathology 24 707-709. (doi:10.1177/019262339602400605)

Luetjens CM \& Wesselmann R 2007 The fate of paternal mitochondria in marmoset embryos. Journal of Medical Primatology 37 128-140. (doi:10.1111/j.1600-0684.2007.00252.x)

Luetjens CM, Weinbauer GF \& Wistuba J 2005 Primate spermatogenesis: new insights into comparative testicular organisation, spermatogenic efficiency and endocrine control. Biological Reviews of the Cambridge Philosophical Society 80 475-488. (doi:10.1017/S1464793105006755)

Marshall GR, Wickings EJ, Lüdecke DK \& Nieschlag E 1983 Stimulation of spermatogenesis in stalk-sectioned rhesus monkeys by testosterone alone. Journal of Clinical Endocrinology and Metabolism 57 152-159. (doi:10.1210/jcem-57-1-152)

Marshall GR, Jockenhövel F, Lüdecke D \& Nieschlag E 1986 Maintenance of complete but quantitatively reduced spermatogenesis in hypophysectomized monkeys by testosterone alone. Acta Endocrinologica 113 424-431. (doi:10.1530/acta.0.1130424)

Meriggiola MC, Costantino A, Saad F, D'Emidio L, Morselli Labate AM, Bertaccini A, Bremner WJ, Rudolph I, Ernst M, Kirsch B et al. 2005 Norethisterone enanthate plus testosterone undecanoate for male contraception: effects of various injection intervals on spermatogenesis, reproductive hormones, testis, and prostate. Journal of Clinical Endocrinology and Metabolism 90 2005-2014. (doi:10.1210/ jc.2004-1852)

Millar MR, Sharpe RM, Weinbauer GF, Fraser HM \& Saunders PT 2000 Marmoset spermatogenesis: organizational similarities to the human. International Journal of Andrology 23 266-277. (doi:10.1046/j.13652605.2000.00236.x)

Mitchell RT, Cowan G, Morris KD, Anderson RA, Fraser HM, Mckenzie KJ, Wallace WH, Kelnar CJ, Saunders PT \& Sharpe RM 2008 Germ cell differentiation in the marmoset (Callithrix jacchus) during fetal and neonatal life closely parallels that in the human. Human Reproduction 23 2755-2765. (doi:10.1093/humrep/den295)

Mohle U, Heistermann M, Palme R \& Hodges JK 2002 Characterization of urinary and fecal metabolites of testosterone and their measurement for assessing gonadal endocrine function in male nonhuman primates. General and Comparative Endocrinology 129 135-145. (doi:10.1016/ S0016-6480(02)00525-7)

Müller T, Simoni M, Pekel E, Luetjens CM, Chandolia R, Amato F, Norman RJ \& Gromoll J 2004 Chorionic gonadotrophin $\beta$ subunit mRNA but not luteinising hormone $\beta$ subunit mRNA is expressed in the pituitary of the common marmoset (Callithrix jacchus). Journal of Molecular Endocrinology 32 115-128. (doi:10.1677/jme.0.0320115)

Müller T, Hupfeld T, Roessler J, Simoni M, Gromoll J \& Behr R 2011 Molecular cloning and functional characterization of endogenous recombinant common marmoset monkey (Callithrix jacchus) folliclestimulating hormone. Journal of Medical Primatology 40 111-119. (doi:10.1111/j.1600-0684.2010.00453.x)

Nieschlag E 2010 Clinical trials in male hormonal contraception. Contraception 82 457-470. (doi:10.1016/j.contraception.2010.03.020)

Nieschlag E \& Loriaux DL 1972 Radioimmunoassay for plasma testosterone. Zeitschrift für Klinische Chemie und Klinische Biochemie 10 164-168.

Nievergelt CM, Digby LJ, Ramakrishnan U \& Woodruff DS 2000 Genetic analysis of group composition and breeding system in a wild common marmoset (Callithrix jacchus) population. International Journal of Primatology 21 1-20. (doi:10.1023/A:1005411227810)

Pugeat M, Rocle B, Chrousos GP, Dunn JF, Lipsett MB \& Nisula BC 1984 Plasma testosterone transport in primates. Journal of Steroid Biochemistry 20 473-478. (doi:10.1016/0022-4731(84)90256-5)

Pryce CR, Palme R \& Feldon J 2002 Development of pituitary-adrenal endocrine function in the marmoset monkey: infant hypocortisolism is the norm. Journal of Clinical Endocrinology and Metabolism 87 691-699. (doi:10.1210/jc.87.2.691)
Ross CN, French JA \& Patera KJ 2004 Intensity of aggressive interactions modulates testosterone in male marmosets. Physiology \& Behavior 83 437-445. (doi:10.1016/j.physbeh.2004.08.036)

Saltzman W, Digby LJ \& Abbott DH 2009 Reproductive skew in female common marmosets: what can proximate mechanisms tell us about ultimate causes? Proceedings of the Royal Society of London. Series B: Biological Sciences 276 389-399. (doi:10.1098/rspb.2008.1374)

Selice R, Ferlin A, Garolia A, Caretta N \& Foresta C 2011 Effects of endogenous FSH on normal human spermatogenesis in adults. International Journal of Andrology 34 e511-e517. (doi:10.1111/j.13652605.2010.01134.x)

Shinki T, Shiina Y, Takahashi N, Tanioka Y, Koizumi H \& Suda T 1983 Extremely high circulating levels of $1 \alpha, 25$-dihydroxyvitamin D3 in the marmoset, a New World Monkey. Biochemical and Biophysical Research Communications 114 452-457. (doi:10.1016/0006-291X(83) 90801-X)

Sousa MB, Leão AC, Coutinho JF \& de Oliveira Ramos AM 2008 Histopathology findings in common marmosets (Callithrix jacchus Linnaeus, 1758) with chronic weight loss associated with bile tract obstruction by infestation with Platynosomum (Loos, 1907). Primates 49 283-287. (doi:10.1007/s10329-008-0105-2)

Takahashi N, Suda S, Shinki T, Horuchi N, Shiina Y, Tanioka Y, Koizumi H \& Suda T 1985 The mechanism of end-organ resistance to $1 \alpha, 25$ dihydroxycholecalciferol in the common marmoset. Biochemical Journal 227 555-563.

Weinbauer GF \& Nieschlag E 1999 Testicular physiology of primates. In Reproduction in Nonhuman Primates: a Model System for Human Reproductive Physiology and Toxicology, pp 13-26. Eds GF Weinbauer\& R Korte. Muenster/New York: Waxmann Publisher.

Weinbauer GF, Schubert J, Yeung CH, Rosiepen G \& Nieschlag E 1998 Gonadotrophin-releasing hormone antagonist arrests premeiotic germ cell proliferation but does not inhibit meiosis in the male monkey: a quantitative analysis using 5-bromodeoxyuridine and dual parameter flow cytometry. Journal of Endocrinology 156 23-34. (doi:10.1677/ joe.0.1560023)

Weinbauer GF, Aslam H, Krishnamurthy H, Brinkworth MH, Einspanier A \& Hodges JK 2001a Quantitative analysis of spermatogenesis and apoptosis in the common marmoset (Callithrix jacchus) reveals high rates of spermatogonial turnover and high spermatogenic efficiency. Biology of Reproduction 64 120-126. (doi:10.1095/biolreprod64.1.120)

Weinbauer GF, Schlatt S, Walter V \& Nieschlag E $2001 b$ Testosteroneinduced inhibition of spermatogenesis is more closely related to suppression of FSH than to testicular androgen levels in the cynomolgus monkey model (Macaca fascicularis). Journal of Endocrinology 168 25-38. (doi:10.1677/joe.0.1680025)

Wistuba J, Schrod A, Greve B, Hodges JK, Aslam H, Weinbauer GF \& Luetjens CM 2003 Organization of seminiferous epithelium in primates: relationship to spermatogenic efficiency, phylogeny, and mating system. Biology of Reproduction 69 582-591. (doi:10.1095/biolreprod.103. 015925)

Wistuba J, Marc Luetjens C, Kamischke A, Gu YQ, Schlatt S, Simoni M \& Nieschlag E 2005 Pharmacokinetics and pharmacodynamics of injectable testosterone undecanoate in castrated cynomolgus monkeys (Macaca fascicularis) are independent of different oil vehicles. Journal of Medical Primatology 34 178-187. (doi:10.1111/j.1600-0684.2005. 00115.x)

Wistuba J, Nieschlag E, Semjonow A, Sandhowe-Klaverkamp R, Friderichs-Gromoll S, Zitzmann M, Simoni M \& Luetjens CM 2012 Testosterone-induced prostate growth is blocked by co- and preadministration of norethisterone enanthate (NETE) in castrated cynomolgous monkeys (Macaca fascicularis). Urologia Internationalis 88 358-364. (doi:10.1159/000335209)

Received 26 September 2012

First decision 29 October 2012

Revised manuscript received 29 January 2013

Accepted 19 February 2013 